\title{
The activity of a mammalian proline-rich peptide against Gram-negative bacteria, including drug- resistant strains, relies on a nonmembranolytic mode of action
}

This article was published in the following Dove Press journal: Infection and Drug Resistance

\author{
Tecla Ciociola' \\ Laura Giovati' \\ Angela Giovannelli ${ }^{2}$ \\ Stefania Conti' \\ Massimo Castagnola ${ }^{2,3}$ \\ Alberto Vitali ${ }^{3}$ \\ 'Department of Medicine and \\ Surgery, University of Parma, Parma, \\ ${ }^{2}$ Institute of Biochemistry and Clinical \\ Biochemistry, Catholic University, \\ Rome, ${ }^{3}$ Institute for the Chemistry \\ of Molecular Recognition, C.N.R., c/o \\ Institute of Biochemistry and Clinical \\ Biochemistry, Catholic University, \\ Rome, Italy
}

Background: A peptide of 2,733 Da named SP-E, previously isolated from pig saliva and already described for its antifungal activity and absence of toxicity against mammalian cells, is characterized by a high content of proline residues ( $70 \%$ of entire sequence), that confer structural features probably related to peptide activity.

Purpose: The aim of this study was to evaluate the activity of SP-E against Gram-negative bacteria, including drug-resistant clinical isolates.

Methods: SP-E and shorter fragments of the same peptide were tested in vitro against the selected bacteria by colony forming unit assays. Scanning electron microscopy and confocal microscopy were also applied. SP-E potential therapeutic activity was evaluated in vivo in a Galleria mellonella model of bacterial infection.

Results: SP-E proved to be active against the tested bacteria with $\mathrm{EC}_{50}$ values in the micromolar range. Though maintaining antibacterial properties, the shorter peptides showed lower activity in respect to the parental molecule. Kinetics of killing action and nonmembranolytic internalization within Escherichia coli and Pseudomonas aeruginosa cells strongly suggested a cytosolic mechanism of action involving one or more intracellular molecular targets. A single injection of SP-E exerted a therapeutic effect in $G$. mellonella larvae infected with P. aeruginosa. Conclusion: The biological properties of SP-E strongly back this peptide as a new promising multitasking antimicrobial molecule.

Keywords: antimicrobial peptide, proline-rich peptides, drug-resistant bacteria, confocal microscopy, scanning electron microscopy, Galleria mellonella model

\section{Introduction}

The increasing need for new drugs able to counteract the emerging threat of resistant bacteria makes the study of antimicrobial peptides (AMPs) as possible alternative or at least complementary therapeutic agents even more significant. Most of the known AMPs exert their activity against bacteria by disrupting and breaking the biophysical equilibrium of the plasma membranes through different mechanisms. ${ }^{1-4}$ However, some AMPs kill bacteria by mechanisms different from membrane perturbation. ${ }^{5-7}$ These AMPs may interact with molecular cellular targets (DNA, RNA, and proteins), impairing some vital biochemical processes (eg, DNA replication, protein synthesis, and enzyme activities) with different modes of action.

A peculiar class of these bactericidal molecules is represented by the proline-rich AMPs (PrAMPs), the archetype of AMPs, showing nonmembranolytic effects. ${ }^{7-9}$ The dis-
Correspondence: Stefania Conti Department of Medicine and Surgery, University of Parma, 39 Via Volturno, Parma 43I 25, Italy

Tel +390521903492

$\mathrm{Fax}+390521903802$

Email stefania.conti@unipr.it 
covery of PrAMPs firstly occurred in certain insects with the identification of apidaecins, ${ }^{10}$ followed by the characterization of additional insect and mammalian PrAMPs. Insect PrAMPs include drosocin from Drosophila melanogaster, ${ }^{11}$ abaecins from Apis mellifera, ${ }^{12}$ pyrrhocoricins, ${ }^{13}$ metalnikowin 1 from the bug Palomena prasina,${ }^{14}$ and oncocin from the milkweed bug Oncopeltus fasciatus. ${ }^{15,16}$ Penaeidins are a varied family of PrAMPs found in crustaceans. These peptides are peculiar, as they are composed of two domains, an N-terminal prolinerich domain and a $\mathrm{C}$-terminal cysteine-rich domain containing six cysteine residues engaged in three disulfide bridges. Penaeidins are characterized by great structural diversity, leading to classification into diverse subfamilies differing in antimicrobial features. ${ }^{17}$ In mammals, bactenecins are the bestknown examples of PrAMPs, together with the PR39 peptide isolated from pig neutrophils. ${ }^{18}$ Similarly to bovine bactenecins, the ovine counterparts OaBac5, OaBac6, OaBac7.5, and OaBac $11^{19}$ and goat ChBac5 have been characterized.

Our group isolated from pig saliva two antifungal PrAMPs, SP-B and SP-E, ${ }^{20,21}$ whose structural features were characterized by means of circular dichroism and Fourier-transform infrared spectroscopy. Both peptides were noncytotoxic when challenged against 3T3 and MEWO cells. SP-E has also been studied and patented for its anti-HIV1 activity ${ }^{22}$ and found to be a multitarget peptide. In this study, we investigated the activity of SP-E peptide against different Gram-negative bacterial strains, including multiresistant clinical isolates. The modalities of killing and the cell-penetrating properties of SP-E strongly suggest that this peptide, as other PrAMPs, exerts its bactericidal activity through interaction with intracellular molecular targets. Current studies are aimed at revealing the molecular mechanisms underlying SP-E antibacterial activity.

\section{Materials and methods}

\section{Chemicals}

Unless otherwise specified, all chemicals were purchased from Sigma-Aldrich (St Louis, MO, USA). Synthesis of peptide SP-E (N-DKPKKKPPPPAGPPPPPPPPPGPPPPGPC), its shorter fragments SP-E22 and SP-E13, and SP-E coupling with 5-carboxyfluorescein (5-FAM) were carried out as already reported. ${ }^{21}$ Eumenitin, a previously described cationic linear $\alpha$-helical AMP, ${ }^{23}$ was obtained through a peptide-synthesis service (ProteoGenix, Schiltigheim, France).

\section{Bacterial strains}

Well-known Gram-negative reference strains and clinical isolates were used in this study. Escherichia coli ATCC 25922, Pseudomonas aeruginosa ATCC 9027, and Salmonella typhimurium ATCC 14028 were the reference strains. Six clinical isolates (two Acinetobacter baumannii, the first from a blood culture and the second from sputum, two E. coli from urine cultures, and two Klebsiella pneumoniae from blood cultures) characterized by different antimicrobial susceptibility profiles (Table 1) were kindly provided by Professor Giulia Morace, University of Milan, Italy; they were not specifically isolated for this research but were part of the routine hospital laboratory procedure.

\section{Antibacterial assays}

Peptide activity in vitro against Gram-negative bacteria was assessed by colony-forming unit (CFU) assays. Bacterial strains to be tested were grown in Müller-Hinton (MH) agar plates at $37^{\circ} \mathrm{C}$ for 24 hours. Bacterial cells were suspended in $\mathrm{MH}$ broth, then properly diluted in sterile distilled water (1.5$3 \times 10^{4}$ cells $/ \mathrm{mL}$ ) and $10 \mu \mathrm{L}$ suspensions added to $90 \mu \mathrm{L} \mathrm{H}_{2} \mathrm{O}$ containing the synthetic peptide at different concentrations $(5-150 \mu \mathrm{g} / \mathrm{mL}) . \mathrm{H}_{2} \mathrm{O}$ alone served as control. After incubation for 5 hours at $37^{\circ} \mathrm{C}$, the bacterial cells were dispensed and streaked on the surface of $\mathrm{MH}$ agar plates. After incubation for $24-48$ hours at $37^{\circ} \mathrm{C}$, colonies were enumerated. Each assay was performed in triplicate. At least two independent experiments were performed for each condition, and in all cases, variability was $<10 \%$. Peptide activity was determined as the percentage of CFU inhibition according to the formula

Table I Susceptibility profiles of analyzed Gram-negative clinical isolates

\begin{tabular}{|c|c|c|c|c|c|c|c|c|c|c|c|c|c|c|c|c|c|c|}
\hline \multirow[t]{2}{*}{ Strain } & \multicolumn{18}{|c|}{ Antimicrobial susceptibility profile } \\
\hline & AMK & AMC & AMP & FEP & CTX & CAZ & CIP & CS & ETP & FOS & GM & IPM & MEM & $\mathbf{F}$ & NOR & TZP & SXT & ESBL \\
\hline Acinetobacter baumannii I & & $\mathrm{R}$ & & $\mathrm{R}$ & $\mathrm{R}$ & $\mathrm{R}$ & S & $S$ & & $\mathrm{R}$ & S & S & $S$ & & & & S & \\
\hline A. baumannii 2 & & $\mathrm{R}$ & & $\mathrm{R}$ & $\mathrm{R}$ & $\mathrm{R}$ & $\mathrm{R}$ & $S$ & & $\mathrm{R}$ & $\mathrm{R}$ & R & $\mathrm{R}$ & & & & $\mathrm{R}$ & \\
\hline Escherichia coli I & $S$ & $\mathrm{R}$ & $\mathrm{R}$ & 1 & $\mathrm{R}$ & I & $\mathrm{R}$ & & $S$ & $\mathrm{~S}$ & $\mathrm{~S}$ & S & S & $S$ & $\mathrm{R}$ & $S$ & $\mathrm{R}$ & + \\
\hline E. coli 2 & $S$ & $\mathrm{R}$ & $\mathrm{R}$ & $\mathrm{R}$ & $\mathrm{R}$ & $\mathrm{R}$ & $\mathrm{R}$ & & $S$ & $S$ & $\mathrm{R}$ & S & $S$ & $S$ & $\mathrm{R}$ & $S$ & $\mathrm{R}$ & + \\
\hline Klebsiella pneumoniae I & 1 & $\mathrm{R}$ & & $\mathrm{R}$ & $\mathrm{R}$ & $\mathrm{R}$ & $\mathrm{R}$ & $S$ & & $\mathrm{R}$ & $S$ & $\mathrm{R}$ & $\mathrm{R}$ & & & $\mathrm{R}$ & $\mathrm{R}$ & + \\
\hline K. pneumoniae 2 & $S$ & $\mathrm{R}$ & & $\mathrm{R}$ & $\mathrm{R}$ & $\mathrm{R}$ & $\mathrm{R}$ & $S$ & & $\mathrm{R}$ & $S$ & I & $\mathrm{R}$ & & & $\mathrm{R}$ & $\mathrm{R}$ & + \\
\hline
\end{tabular}

Abbreviations: AMK, amikacin; AMC, amoxicillin-clavulanic acid; AMP, ampicillin; FEP, cefepime; CTX, cefotaxime; CAZ, ceftazidime; CIP, ciprofloxacin; CS, colistin; ETP, ertapenem; FOS, fosfomycin; GM, gentamicin; IPM, imipenem; MEM, meropenem; F, nitrofurantoin; NOR, norfloxacin; TZP, piperacillin-tazobactam; SXT, trimethoprimsulfamethoxazole; ESBL, extended-spectrum $\beta$-lactamase; $R$, resistant; I, intermediate; $S$, sensitive. 
100 - (average number of CFUs in the peptide-treated group/ average number of CFUs in the control group) $\times 100$. Peptide $\mathrm{EC}_{50}$ was calculated by nonlinear regression analysis using GraphPad Prism 4.01 software. Time kinetics of peptidemediated killing of selected bacterial strains were evaluated by CFU assays, as previously described, at different times of incubation (30, 60, 120, 240, and 300 minutes). The peptide was used at a concentration near to the minimal bactericidal, as assessed by previous CFU assays.

\section{Evaluation of in vivo therapeutic activity of SP-E}

In vivo potential therapeutic effects of SP-E were studied in the Galleria mellonella model..$^{24,25}$ Groups of 16 larvae at their final instar stage (body weight $300 \pm 20 \mathrm{mg}$ ) were inoculated (10 $\mu \mathrm{L} /$ larva) directly in the hemocoel, via the last left proleg, with a $P$. aeruginosa ATCC 9027 suspension $\left(3 \times 10^{3}\right.$ cells/ $\mathrm{mL}$ ). Thirty minutes after infection, larvae (16/group) were injected via the last right proleg (single injection of $10 \mu \mathrm{L}$ ) with the peptide $(6.1 \mu \mathrm{mol} / \mathrm{kg})$ or water (control). Further controls included untouched larvae and larvae injected with water alone to monitor the trauma. Larvae were then transferred to clean petri dishes (one for each experimental group), incubated at $37^{\circ} \mathrm{C}$ in the dark for 6 days, and scored daily for survival. Survival curves of peptide-treated and control animals were compared by the Mantel-Cox log-rank test using GraphPad Prism software. $P<0.05$ was considered significant.

\section{Scanning electron microscopy (SEM)}

After treatment with different concentrations of SP-E (3 and 30 $\mu \mathrm{M})$, bacteria were fixed in $2.5 \%$ glutaraldehyde for 2 hours and then dehydrated serially in ethanol solutions. After drying, the samples were sputtered with gold and micrographs acquired, using a Supra 25 microscope (Carl Zeiss, Jena, Germany).

\section{Confocal laser-scanning microscopy}

Confocal microscopy studies were performed with an LSM 510 metascan head integrated with an Axiovert $200 \mathrm{M}$ inverted microscope (Carl Zeiss) as previously described, with minor modifications. ${ }^{21}$ Living bacterial cells were incubated with 5-FAM-labeled peptide for 5, 120, and 240 minutes at room temperature in the dark. After centrifugation $(5,000 \mathrm{~g}, 5$ minutes $)$, the cell pellet was resuspended in 20 $\mu \mathrm{L}$ of water with agarose $(1 \%)$. The suspension was seeded on coverslips mounted in a special flow chamber. Propidium iodide (PI), a nonvital nuclear stain commonly used for identifying dead cells, was added. Images were taken immediately and after 15 and 30 minutes. Samples were observed through a $63 \times$ NA 1.4 Plan Apo oil objective. PI and 5-FAM were excited with $543 \mathrm{~nm} \mathrm{He}-\mathrm{Ne}$ and $488 \mathrm{~nm}$ argon laser lines, respectively. Acquisition was carried out in multitrack mode through consecutive and independent optical pathways.

\section{Results}

\section{Antibacterial activity in vitro}

In the present study, SP-E proline-rich peptide was challenged against different Gram-negative bacteria, including multiresistant clinical isolates, as shown in Table 1. SP-E proved to be active against all the bacterial strains tested (Table 2), with the best $\mathrm{EC}_{50}$ values toward E. coli ATCC $25922(3.3 \mu \mathrm{M})$ and $P$. aeruginosa ATCC $9027(2.7 \mu \mathrm{M})$. Though to a lower extent, SP-E was also active against resistant strains of $A$. baumannii and $K$. pneumoniae. The dose-dependent effect of SP-E against selected bacterial strains of the different species tested is shown in Figure S1. Time-killing curves, determined against $E$. coli ATCC 25922, P. aeruginosa 9027 , and $A$. baumannii 2 strains with SP-E at concentration values corresponding approximately to the previously determined minimal bactericidal concentration, demonstrated a slow bactericidal effect. In particular, just over $26 \%$ and $41 \%$ killing was observed against $E$. coli at 30 and 60 minutes, respectively, while killing was virtually nil against $A$. baumannii at 30 minutes and only $37 \%$ at 60 minutes (Figure $1 \mathrm{~A}$ and $\mathrm{C}$ ). Faster killing was observed against $P$. aeruginosa, as almost $50 \%$ and $>70 \%$ cells were dead after 30 and 60 minutes, respectively, in the presence of SP-E (Figure 1B).

\section{Structure-activity relationship}

The primary sequence of SP-E is almost peculiar, being formed by an N-terminal highly polar and basic domain (one Asp and four Lys residues) and a long proline-rich tail.

Table 2 In vitro antibacterial activity of SP-E against Gramnegative bacterial strains

\begin{tabular}{lll}
\hline Bacterial strains & EC $_{50}(\mathbf{m o l} / \mathbf{L})$ & $\mathbf{9 5 \% ~ C l}$ \\
\hline Acinetobacter baumannii I & $1.981 \times 10^{-5}$ & $1.946-2.018 \times 10^{-5}$ \\
A. baumannii 2 & $1.053 \times 10^{-5}$ & $0.884-1.254 \times 10^{-5}$ \\
Escherichia coli ATCC 25922 & $3.315 \times 10^{-6}$ & $2.943-3.732 \times 10^{-6}$ \\
E. coli I & $4.292 \times 10^{-6}$ & $2.922-6.301 \times 10^{-6}$ \\
E. coli 2 & $8.511 \times 10^{-6}$ & $8.273-8.760 \times 10^{-6}$ \\
Klebsiella pneumoniae I & $3.304 \times 10^{-5}$ & $2.712-4.025 \times 10^{-5}$ \\
K. pneumoniae 2 & $2.386 \times 10^{-5}$ & $1.798-3.167 \times 10^{-5}$ \\
Pseudomonas aeruginosa ATCC & $2.662 \times 10^{-6}$ & $2.312-3.064 \times 10^{-6}$ \\
9027 & & \\
Salmonella typhimurium ATCC & $1.447 \times 10^{-5}$ & $1.388-1.509 \times 10^{-5}$ \\
I4028 & & \\
\hline
\end{tabular}

Note: Tested strains included multidrug-resistant isolates; SP-E activity was determined by colony-forming unit assays. 
Therefore, in order to understand if structural determinants were present in the sequence, we synthesized two shorter forms of SP-E maintaining the basic head, but with shorter proline tails: SP-E13 and SP-E22. When the two peptides

A

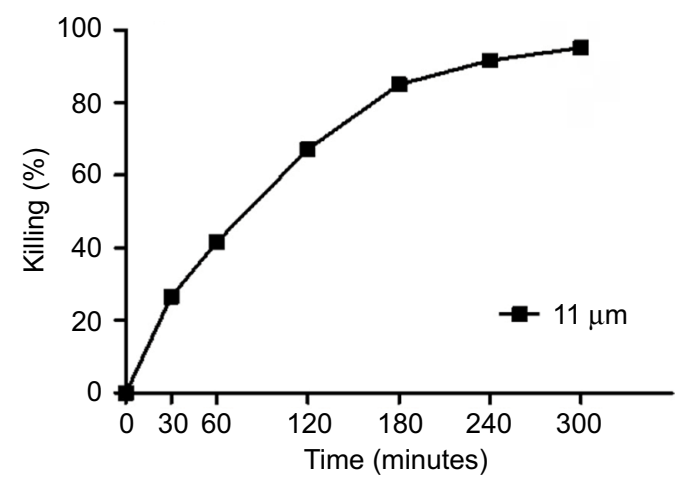

B

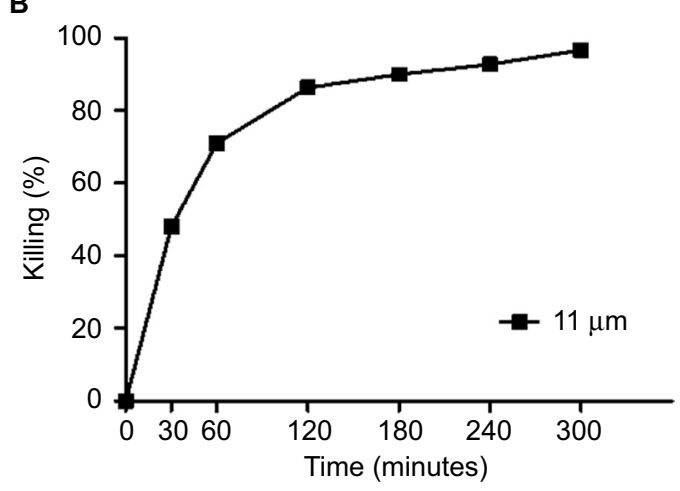

C

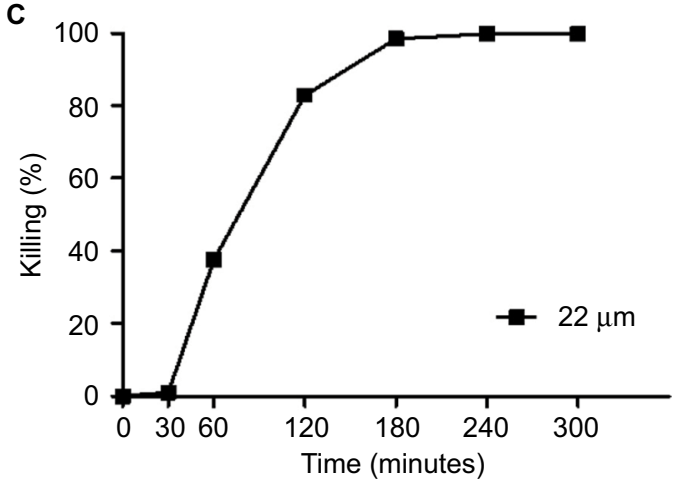

Figure I Time kinetics of in vitro activity of SP-E.

Notes: Against Escherichia coli ATCC 25922 (A), Pseudomonas aeruginosa ATCC 9027 (B), and Acinetobacter baumannii 2 cells (C). Activity expressed as percentage killing, calculated as 100 - (average number of CFUs in peptide-treated group/ average number of CFUs in control group) $\times 100$. Mean values from two independent experiments; in all cases variability $<10 \%$.

Abbreviation: CFUs, colony-forming units. were challenged against the reference strains of $E$. coli and P. aeruginosa, a dramatic decrease in antibacterial activity was observed with respect to the parental peptide SP-E (Table 3). In particular, activity decreased by some magnitude. Moreover, activity diminished with the length of the peptide chain; in fact, the $\mathrm{EC}_{50}$ of the 22-mer form was lower than that of the 13-mer peptide.

\section{In vivo therapeutic activity}

To ascertain the potential of SP-E as a therapeutic agent, we adopted an in vivo model of $G$. mellonella larvae infected with P. aeruginosa 9027 strain $\left(3 \times 10^{3}\right.$ cells $\left./ \mathrm{mL}\right)$. In two independent experiments, a single peptide injection $(10 \mu \mathrm{L}, 6.1 \mu \mathrm{mol} / \mathrm{kg})$ led to a significant increase in survival of larvae in comparison to the control group $(P<0.005)$. In Figure 2, survival curves obtained from one representative experiment are shown. Median survival was 24 hours in the control group vs 144 hours in the peptide-treated group. Notably, at 6 days postinfection, 14 of 16 larvae of the control group were dead, whereas eight larvae of the peptide-treated group were still alive.

\section{SEM and confocal microscopy studies}

Time-killing curves evidenced that SP-E acted slowly in killing bacteria, resembling in this aspect other PrAMPs that exploit their antibacterial activity without a membranolytic effect. ${ }^{7-9}$ With the aim of better understanding the modality of killing of SP-E through visualization of the effect on bacteria morphology, SEM experiments were performed using different SP-E-peptide concentrations, ie, $3 \mu \mathrm{M}$ (near the $\left.\mathrm{EC}_{50}\right)$ and an excess of the lethal dose $(30 \mu \mathrm{M})$. The pore-forming peptide eumenitin ${ }^{26}$ was used at its minimum inhibitory concentration (MIC) as a control. SEM images of untreated $E$. coli cells showed a bright, smooth surface (Figure 3A). No effect was exerted by SP-E at even the higher concentration, well above the lethal one (Figure 3B and $\mathrm{C}$ ). Conversely, eumenitin caused evident damage to bacterial cells (Figure 3D). We further investigated the possible fate of SP-E in the interaction with bacterial cells. SP-E has proved to be internalized by Cryptococcus neoformans cells, ${ }^{21}$ and thus we would expect to observe similar behavior, even with bacteria. Confocal micros-

Table 3 In vitro activity of peptides SP-E22 and SP-EI 3 against reference bacterial strains determined by colony-forming unit assays

\begin{tabular}{|c|c|c|c|c|}
\hline \multirow[t]{2}{*}{ Bacterial strains } & \multicolumn{2}{|c|}{ SP-E22 (DKPKKKPPPPAGPPPPPPPPPG) } & \multicolumn{2}{|c|}{ SP-E I 3 (DKPKKKPPPPAGP) } \\
\hline & $\mathrm{EC}_{50}(95 \% \mathrm{Cl})(\mathrm{mol} / \mathrm{L})$ & $\mathrm{EC}_{50} / \mathrm{EC}_{50}$ SP-E & $\mathrm{EC}_{50}(95 \% \mathrm{Cl})(\mathrm{mol} / \mathrm{L})$ & $E C_{50} / E C_{50}$ SP-E \\
\hline Escherichia coli ATCC 25922 & $1.005(0.911-1.108) \times 10^{-5}$ & 3.03 & $2.891(2.699-3.097) \times 10^{-5}$ & 8.72 \\
\hline Pseudomonas aeruginosa ATCC 9027 & $1.380(0.762-2.498) \times 10^{-5}$ & 5.18 & $2.121(1.498-3.005) \times 10^{-5}$ & 7.97 \\
\hline
\end{tabular}




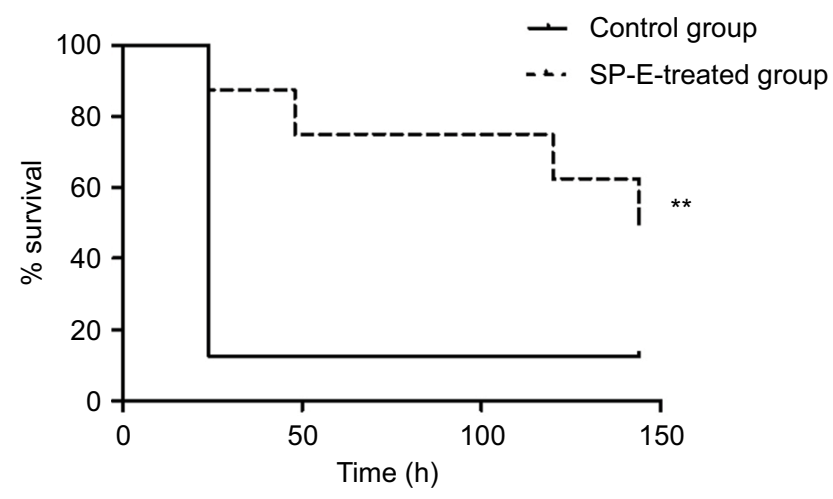

Figure 2 Therapeutic activity of SP-E.

Notes: Groups of 16 Galleria mellonella larvae were infected with $3 \times 10^{3}$ cells $/ \mathrm{mL}$ of Pseudomonas aeruginosa ATCC 9027 and treated with SP-E $(6.1 \mu \mathrm{mol} / \mathrm{kg}$, single injection of $10 \mu \mathrm{L}$ ) or water (control group). The survival curve of peptide-treated larvae was significantly different from that of the control group, as assessed by Mantel-Cox log-rank test $\left({ }^{* *} P<0.005\right)$. Data reported are from one representative experiment of two experiments with comparable results.
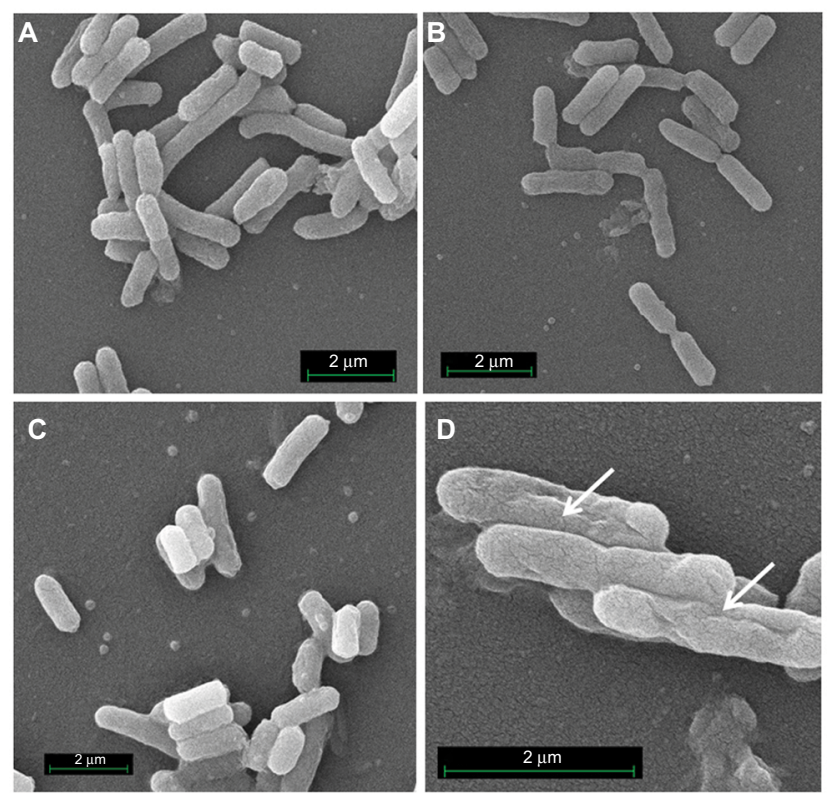

Figure 3 SEM of Escherichia coli cells treated with SP-E and eumenitin.

Notes: (A) Untreated control cells; (B) cells treated with SP-E $3 \mu \mathrm{M}$; (C) cells treated with SP-E $30 \mu \mathrm{M}$; and (D) cells treated with eumenitin at its MIC $(3 \mu \mathrm{M})$. $^{23}$ Arrows indicate membrane damage caused by eumenitin.

Abbreviations: SEM, scanning electron microscopy; MIC, minimum inhibitory concentration.

copy allowed the investigation of the interaction between 5-FAM-labeled SP-E and viable bacteria. SP-E was readily internalized in both E. coli (Figure 4A) and P. aeruginosa (Figure 5A) cells. After 120 minutes, some bacterial cells were no longer viable, as assessed by PI internalization $(E$. coli $[$ Figure $4 \mathrm{~B}-\mathrm{D}]$ and $P$. aeruginosa $[$ Figure 5B-D]). After 240 minutes of incubation in the presence of SP-E, more bacterial cells were dead, but while viable $E$. coli were still fluorescent (Figure 4E-G), most $P$. aeruginosa cells were not labeled, and fluorescence appeared diffused outside the cells (Figure 5E-G). Quantitative data obtained in confocal microscopy studies are presented in Figure S2.

\section{Discussion}

In view of the global spread of antimicrobial-resistant bacteria, the urgent need for new and effective drugs is generally recognized. AMPs play an important role as potential candidates to substitute for or be used in association with conventional antibacterial drugs. In this study, we focused our attention on a proline-rich peptide already studied for its antiviral and antifungal activities. It was patented as an anti-HIV agent, being able to inhibit the proliferation of the virus in vitro and ex vivo, ${ }^{22}$ then its antifungal properties, particularly against $C$. neoformans, were described. ${ }^{21}$ In addition to its antimicrobial features, it must be highlighted that SP-E does not present cytotoxic effects toward mammalian cells, as previously reported. ${ }^{21,22}$ The data now presented show that SP-E to various degrees is able to kill different Gram-negative bacteria, including multidrug-resistant K. pneumoniae, E. coli, and A. baumannii strains. These bacteria are considered highly threatening species, especially in nosocomial settings, and are included in the priority 1 critical group, in the frame of the priority-pathogen list for research and development of new antibiotics recently issued by the World Health Organization. ${ }^{27}$ The data collected on the effects of SP-E on viability and morphology of the model strains E. coli ATCC 25922 and P. aeruginosa 9027 strongly suggest that this PrAMP does not exert its antibacterial activity acting as a membranolytic agent but likely exploits a more specific molecular mechanism of action involving one or more intracellular targets.

This hypothesis is supported by two main facts: the relatively slow killing action and the lack of simultaneity between peptide internalization and death of bacterial cells, a typical feature of membrane-disrupting peptides. ${ }^{28}$ Amphipathic AMPs exerting a direct effect on membranes usually kill bacterial cells rapidly in 5-30 minutes. ${ }^{3}$ SP-E instead reaches its maximal bactericidal effect after 120-240 minutes, depending on the concentration and the target strain, and shows killing kinetics similar to other PrAMPs, ${ }^{28-30}$ even if internalization occurs in a few minutes. The difference in the killing kinetics between the three bacterial strains tested probably indicates a different modality of internalization and/or intracellular action. In a recent paper, Runti et al observed how Bac7(1-35) was able to kill some $P$. aeruginosa clinical isolates by disrupting bacterial membrane, thus acting in a completely different 


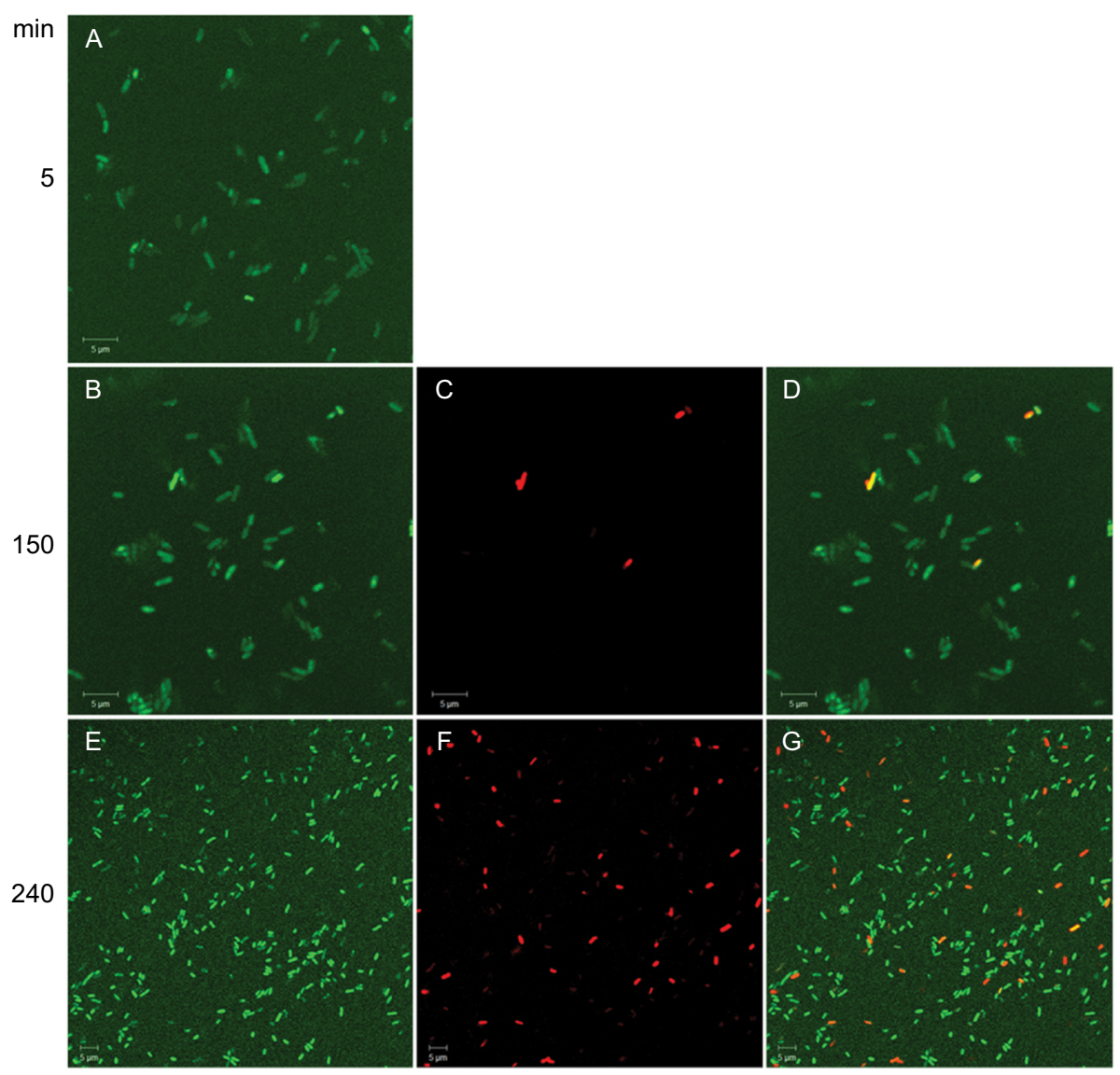

Figure 4 Internalization of SP-E in Escherichia coli ATCC 25922 cells.

Notes: Confocal images of living bacterial cells incubated in the presence of 5-FAM-labeled SP-E for 5 minutes (A), 150 minutes (B), and 240 minutes (E). SP-E entered most bacterial cells within a few minutes; after 150 minutes, some bacterial cells were brightly fluorescent and no longer viable, as assessed by propidium iodide internalization (C and $\mathbf{D}$ [merge of $\mathbf{B}$ and $\mathbf{C}$ ]). After 240 minutes of incubation in the presence of SP-E, more cells were dead (F and $\mathbf{G}$ [merge of $\mathbf{E}$ and $\mathbf{F}$ ]). Bars, $5 \mu \mathrm{m}$.

Abbreviation: 5-FAM, 5-carboxyfluorescein.

mode with respect to $E$. coli and Salmonella enterica serovar Typhimurium. These authors suggest that depending on the species and strain treated, different mechanisms of killing may occur. ${ }^{31}$

Previously tested in a phospholipid-vesicle-based assay, SP-E showed no ability to perturb membrane integrity in the experimental model, even at concentrations up to $100 \mu \mathrm{M} .{ }^{21}$ In this study, SEM experiments involving E. coli ATCC 25922 cells treated with SP-E up to tenfold the $\mathrm{EC}_{50}(30$ $\mu \mathrm{M})$, showed no alteration of bacterial morphology. Confocal microscopy images confirmed that SP-E can enter bacterial cells of $E$. coli and $P$. aeruginosa within a few minutes, yet cells maintain their integrity and viability for a long period, as assessed by PI staining. Similar behavior was observed in our previous study, where SP-E demonstrated its good cell-penetrating properties, entering C. neoformans cells and causing their death. ${ }^{21}$

Other PrAMPs proved to exhibit a dual mode of action dependent on the concentration used. Bac7, for example, when used at a concentration near MIC, behaves as a typical
PrAMP, entering cells and killing them by interacting with intracellular molecular targets. ${ }^{29}$ Similarly, the peptide arasin 1 shows a double mode of action, causing membrane disruption at high concentrations and acting on intracellular targets at MIC values. ${ }^{30}$ Also indolicidin, a proline- and tryptophanrich peptide, behaves as a membrane-disrupting peptide when used at concentrations $>2.6 \mu \mathrm{M} .{ }^{32}$ SP-E behavior seems to rely - also at high concentrations - on a different mechanism, probably involving specific binding to intracellular molecular targets. This hypothesis and mechanisms of entrance and killing will be confirmed by further experiments.

The shorter forms of SP-E, SP-E13, and SP-E22 proved to be less active than the parental peptide, indicating a strong relationship between activity and length of the peptide chain. To obtain these peptides, SP-E was shortened in its $\mathrm{C}$-terminal portion, leaving intact the $\mathrm{N}$-terminal cationic core considered crucial for its activity. The high percentage of proline residues allows SP-E to adopt a highly flexible structure, while the three intercalated glycine residues act as hinges. ${ }^{21}$ This flexibility may be reduced in shorter peptides 
derived from SP-E, thus explaining their lower efficacy. In fact, it could be hypothesized that a certain flexibility is crucial to allow SP-E targeting of intracellular molecules and its function as a modulator/inhibitor of some protein-protein interactions, thus leading to dysfunction in bacterial cells. ${ }^{33}$ Since SP-E was firstly described as an antifungal peptide, the activity of its shortened derivatives SP-E13 and SP-E22 was also compared against reference yeast strains, likewise demonstrating reduced killing ability with respect to the parental molecule (Table S1).
Another interesting feature of SP-E is that it lacks the typical PRP leitmotif that characterizes most insect and mammalian PrAMPs (Table 4). Instead, the presence of the sequence of DKP residues shared with oncocin and metalnikowin is intriguing. Aspartic acid and lysine residues seem to be crucial for the antibacterial activity of oncocin, which relies on binding to bacterial ribosomes. ${ }^{34}$ In particular, these residues bind some of the $23 \mathrm{~s}$ ribosomal nucleotides occupying the exit tunnel of the forming polypeptide chain, thus presumably blocking peptidyl transferase function.
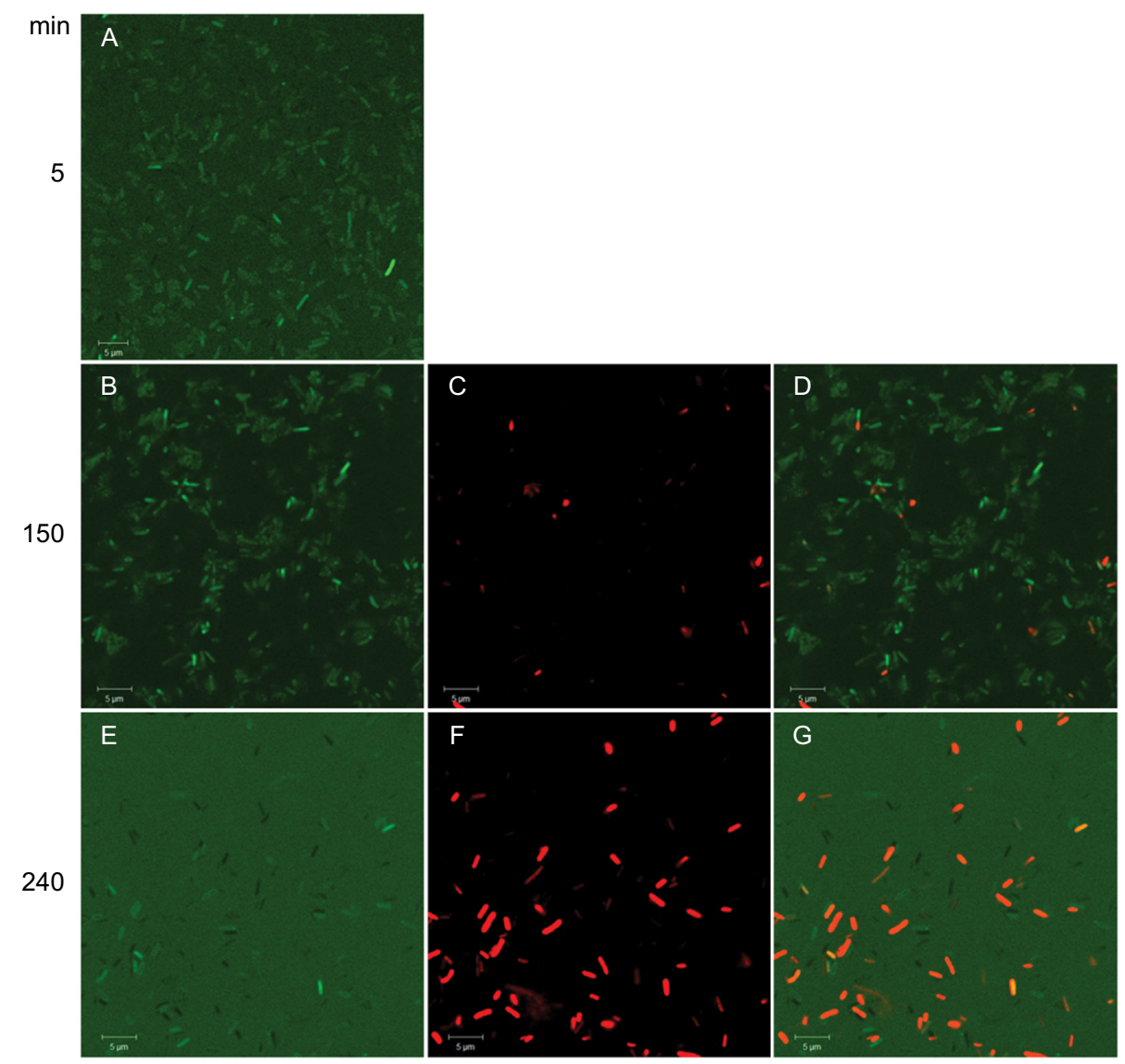

Figure 5 Internalization of SP-E in Pseudomonas aeruginosa ATCC 9027 cells.

Notes: Confocal images of living bacterial cells incubated in the presence of 5-FAM-labeled SP-E for 5 minutes (A), 120 minutes (B), and 240 minutes (E). Most bacterial cells internalized SP-E within a few minutes; after 120 minutes, some bacterial cells were no longer viable, as assessed by propidium iodide internalization (C and $\mathbf{D}$ [merge of $\mathbf{B}$ and C]). After 240 minutes of incubation in the presence of SP-E, more cells were dead, while fluorescence diffused outside the cells $(\mathbf{F}$ and $\mathbf{G}$ [merge of $\mathbf{E}$ and $\mathbf{F}$ ]). Bars, $5 \mu \mathrm{m}$. Abbreviation: 5-FAM, 5-carboxyfluorescein.

Table 4 Comparison of sequences of various antimicrobial proline-rich peptides

\begin{tabular}{|c|c|c|c|}
\hline Peptide & Sequence & PDB ID & Reference \\
\hline $\operatorname{Bac}(1-35)$ & RRIRPRPPRLPRPRPRPLPFPRPGPRPIPRPLPFP & & \\
\hline $\operatorname{Bac}(1-16)$ & RRIRPRPPRLPRPRPR & $5 F 8 K$ & 9 \\
\hline Oncocin & VDKPPYLPRPRPPRRIYNR & $4 Z 8 C$ & 32 \\
\hline Pyrrochoricin & VDKGSYLPRPTPPRPIYNRN & $5 F D V$ & 9 \\
\hline Metalnikowin I & VDKPDYRPRPRPPNM & $5 F D U$ & 9 \\
\hline SP-E & DKPKKKPPPPAGPPPPPPPPPGPPPPGP & & \\
\hline
\end{tabular}

Abbreviation: PDB, Protein Data Bank. 
Moreover, in other PrAMPs and their variants, the N-terminal domain is crucial for ribosome binding and accomplishment of their antibacterial activity. ${ }^{35}$ The DKP motif and following three lysine residues may contribute in a similar fashion to SP-E antibacterial activity. Interestingly, another prolinerich peptide previously isolated and characterized by our group and named SP-B was shown to possess antifungal activity, but when it was challenged with $P$. aeruginosa, negligible antibacterial activity was detected at concentrations $>100 \mu \mathrm{M} .{ }^{20}$ This peptide is characterized by the sequence (N-APPGARPPPGPPPPGPPPPGP-C), which lacks both the DKP and the canonical PRP motifs, suggesting that these short sequences are crucial in exploiting strong antibacterial activity.

Overall, considering the data obtained in this study, SP-E seems to act via an intracellular mechanism. This correlates with data reported for many other PrAMPs, even if SP-E is completely lacking the characteristic PRP pattern usually present in PrAMPs with a nonlytic effect. Further studies will be carried out to identify the intracellular targets of SP-E, both in bacteria and fungi. Given its biological properties, SP-E could be considered a promising molecule for the development of new antimicrobial agents.

\section{Acknowledgments}

We are thankful to Mario Amici of LabCEMI at the Catholic University of Rome for the technical support during SEM experiments. The confocal microscopy images were obtained in the Laboratory of Confocal Microscopy of the Department of Medicine and Surgery of the University of Parma.

\section{Disclosure}

The authors report no conflicts of interest in this work.

\section{References}

1. Dennison SR, Wallace J, Harris F, Phoenix DA. Amphiphilic $\alpha$-helical antimicrobial peptides and their structure/function relationships. Protein Pept Lett. 2005;12:31-39.

2. Splith K, Neundorf I. Antimicrobial peptides with cell-penetrating peptide properties and vice versa. Eur Biophys J. 2011;40:387-397.

3. Lee CC, Sun Y, Qian S, Huang HW. Transmembrane pores formed by human antimicrobial peptide LL-37. Biophys J. 2011;100:1688-1696.

4. Roversi D, Luca V, Aureli S, Park Y, Mangoni ML, Stella L. How many antimicrobial peptide molecules kill a bacterium? The case of PMAP-23. ACS Chem Biol. 2014;9:2003-2007.

5. Cudic M, Otvos L Jr. Intracellular targets of antibacterial peptides. Curr Drug Targets. 2002;2:101-106.

6. Markossian KA, Zamyatnin AA, Kurganov BI. Antibacterial prolinerich oligopeptides and their target proteins. Biochemistry (Mosc). 2004;69:1082-1091.

7. Scocchi M, Tossi A, Gennaro R. Proline-rich antimicrobial peptides: converging to a non-lytic mechanism of action. Cell Mol Life Sci. 2011;68:2317-2330.
8. Graf M, Mardirossian M, Nguyen F, et al. Proline-rich antimicrobial peptides targeting protein synthesis. Nat Prod Rep. 2017;34:702-711.

9. Seefeldt AC, Graf M, Pérébaskine N, et al. Structure of the mammalian antimicrobial peptide Bac7(1-16) bound within the exit tunnel of a bacterial ribosome. Nucleic Acids Res. 2016;44:2429-2438.

10. Li WF, Ma GX, Zhou XX. Apidaecin-type peptides: biodiversity, structure-function relationships and mode of action. Peptides. 2006;27:2350-2359.

11. Bulet P, Urge L, Ohresser S, Hetru C, Otvos L Jr. Enlarged scale chemical synthesis and range of activity of drosocin, an O-glycosylated antibacterial peptide of Drosophila. Eur J Biochem. 1996;238:64-69.

12. Casteels $P, A m p e ~ C$, Riviere L, et al. Isolation and characterization of abaecin, a major antibacterial response peptide in the honeybee (Apis mellifera). Eur J Biochem. 1990;187:381-386.

13. Taniguchi M, Ochiai A, Kondo H, et al. Pyrrhocoricin, a proline-rich antimicrobial peptide derived from insect, inhibits the translation process in the cell-free Escherichia coli protein synthesis system. J Biosci Bioeng. 2016;121:591-598.

14. Chernysh S, Cociancich S, Briand JP, Hetru C, Bulet P. The inducible antibacterial peptides of the hemipteran insect Palomena prasina: identification of a unique family of proline-rich peptides and of a novel insect defensin. J Insect Physiol. 1996;42:81-89.

15. Schneider M, Dorn A. Differential infectivity of two Pseudomonas species and the immune response in the milkweed bug, Oncopeltus fasciatus (Insecta: Hemiptera). J Invertebr Pathol. 2001;78:135-140.

16. Knappe D, Piantavigna S, Hansen A, et al. Oncocin (VDKPPYLPRPRPPRRIYNR-NH $_{2}$ : a novel antibacterial peptide optimized against Gram-negative human pathogens. J Med Chem. 2010;53:5240-5247.

17. Cuthbertson BJ, Deterding LJ, Williams JG, et al. Diversity in penaeidin antimicrobial peptide form and function. Dev Comp Immunol. 2008;32:167-181.

18. Chan YR, Zanetti M, Gennaro R, Gallo RL. Anti-microbial activity and cell binding are controlled by sequence determinants in the antimicrobial peptide PR-39. J Invest Dermatol. 2001;116:230-235.

19. Anderson RC, Yu PL. Isolation and characterisation of proline/argininerich cathelicidin peptides from ovine neutrophils. Biochem Biophys Res Commun. 2003;312:1139-1146.

20. Cabras T, Longhi R, Secundo F, et al. Structural and functional characterization of the porcine proline-rich antifungal peptide SP-B isolated from salivary gland granules. J Pept Sci. 2008;14:251-260.

21. Conti S, Radicioni G, Ciociola T, et al. Structural and functional studies on a proline-rich peptide isolated from swine saliva endowed with antifungal activity towards Cryptococcus neoformans. Biochim Biophys Acta. 2013;1828:1066-1074.

22. Cabras T, Casoli C, Castagnola M, et al, inventors; Società Italiana Brevetti, assignee. Antiviral peptides. World Intellectual Property Organization patent WO/2012/101616. 2012 Aug 2.

23. Konno K, Hisada M, Naoki H, et al. Eumenitin, a novel antimicrobial peptide from the venom of the solitary eumenine wasp Eumenes rubronotatus. Peptides. 2006;27:2624-2631.

24. Desbois AP, Coote PJ. Utility of greater wax moth larva (Galleria mellonella) for evaluating the toxicity and efficacy of new antimicrobial agents. Adv Appl Microbiol. 2012;78:25-53.

25. Hill L, Veli N, Coote PJ. Evaluation of Galleria mellonella larvae for measuring the efficacy and pharmacokinetics of antibiotic therapies against Pseudomonas aeruginosa infection. Int J Antimicrob Agents. 2014;43:254-261.

26. Arcisio-Miranda M, Cabrera MP, Konno K, Rangel M, Procopio J. Effects of the cationic antimicrobial peptide eumenitin from the venom of solitary wasp Eumenes rubronotatus in planar lipid bilayers: surface charge and pore formation activity. Toxicon. 2008;51:736-745.

27. World Health Organization. Global Priority List of Antibiotic-Resistant Bacteria to Guide Research, Discovery, and Development of New Antibiotics. Geneva: WHO; 2017.

28. Podda E, Benincasa M, Pacor S, et al. Dual mode of action of Bac7, a prolinerich antibacterial peptide. Biochim Biophys Acta. 2006;1760:1732-1740.

29. Knappe D, Kabankov N, Hoffmann R. Bactericidal oncocin derivatives with superior serum stabilities. Int JAntimicrobAgents. 2011;37:166-170. 
30. Paulsen VS, Blencke HM, Benincasa M, et al. Structure-activity relationships of the antimicrobial peptide arasin 1 - and mode of action studies of the N-terminal, proline-rich region. PLoS One. 2013;8:e53326.

31. Runti G, Benincasa M, Giuffrida G, et al. The mechanism of killing by the proline-rich peptide Bac7(1-35) against clinical strains of Pseudomonas aeruginosa differs from that against other Gram-negative bacteria. Antimicrob Agents Chemother. 2017;61:e01660-16.

32. Végh AG, Nagy K, Bálint Z, et al. Effect of antimicrobial peptideamide: indolicidin on biological membranes. J Biomed Biotechnol. 2011;2011:670589.
33. Jubb H, Blundell TL, Ascher DB. Flexibility and small pockets at protein-protein interfaces: new insights into druggability. Prog Biophys Mol Biol. 2015;119:2-9.

34. Roy RN, Lomakin IB, Gagnon MG, Steitz TA. The mechanism of inhibition of protein synthesis by the proline-rich peptide oncocin. Nat Struct Mol Biol. 2015;22:466-469.

35. Gagnon MG, Roy RN, Lomakin IB, Florin T, Mankin AS, Steitz TA. Structures of proline-rich peptides bound to the ribosome reveal a common mechanism of protein synthesis inhibition. Nucleic Acids Res. 2016;44:2439-2450. 


\section{Supplementary materials}

Table SI In vitro antifungal activity of peptide SP-E and its shortened derivatives SP-E22 and SP-EI 3 against reference yeast strains

\begin{tabular}{lllll}
\hline Peptide & Fungal strains & $\mathbf{E C}_{50}(\mathbf{m o l} / \mathbf{L})$ & $95 \% \mathbf{C l}$ & EC $_{50} / \mathbf{E C}_{50}$ SP-E \\
\hline SP-E & Cryptococcus neoformans 6995 & $2.215 \times 10^{-6}$ & $1.634-3.003 \times 10^{-6}$ & \\
& Candida albicans SC53I4 & $2.581 \times 10^{-5}$ & $1.658-4.018 \times 10^{-5}$ & 3.75 \\
SP-E22 & C. neoformans 6995 & $8.304 \times 10^{-6}$ & $6.532-10.559 \times 10^{-6}$ & 1.51 \\
& C. albicans SC53I4 & $3.904 \times 10^{-5}$ & $1.984-7.678 \times 10^{-5}$ & 5.53 \\
SP-EI3 & C. neoformans 6995 & $12.251 \times 10^{-6}$ & $9.553-15.715 \times 10^{-6}$ & 2.57 \\
& C. albicans SC53I4 & $6.638 \times 10^{-5}$ & $4.194-10.504 \times 10^{-5}$ & \\
\hline
\end{tabular}

Notes: $\mathrm{EC}_{50}$ calculated by nonlinear regression analysis using GraphPad Prism 4.01 software. Fungicidal activity in vitro assessed by colony-forming unit assays, as previously described. ${ }^{21}$
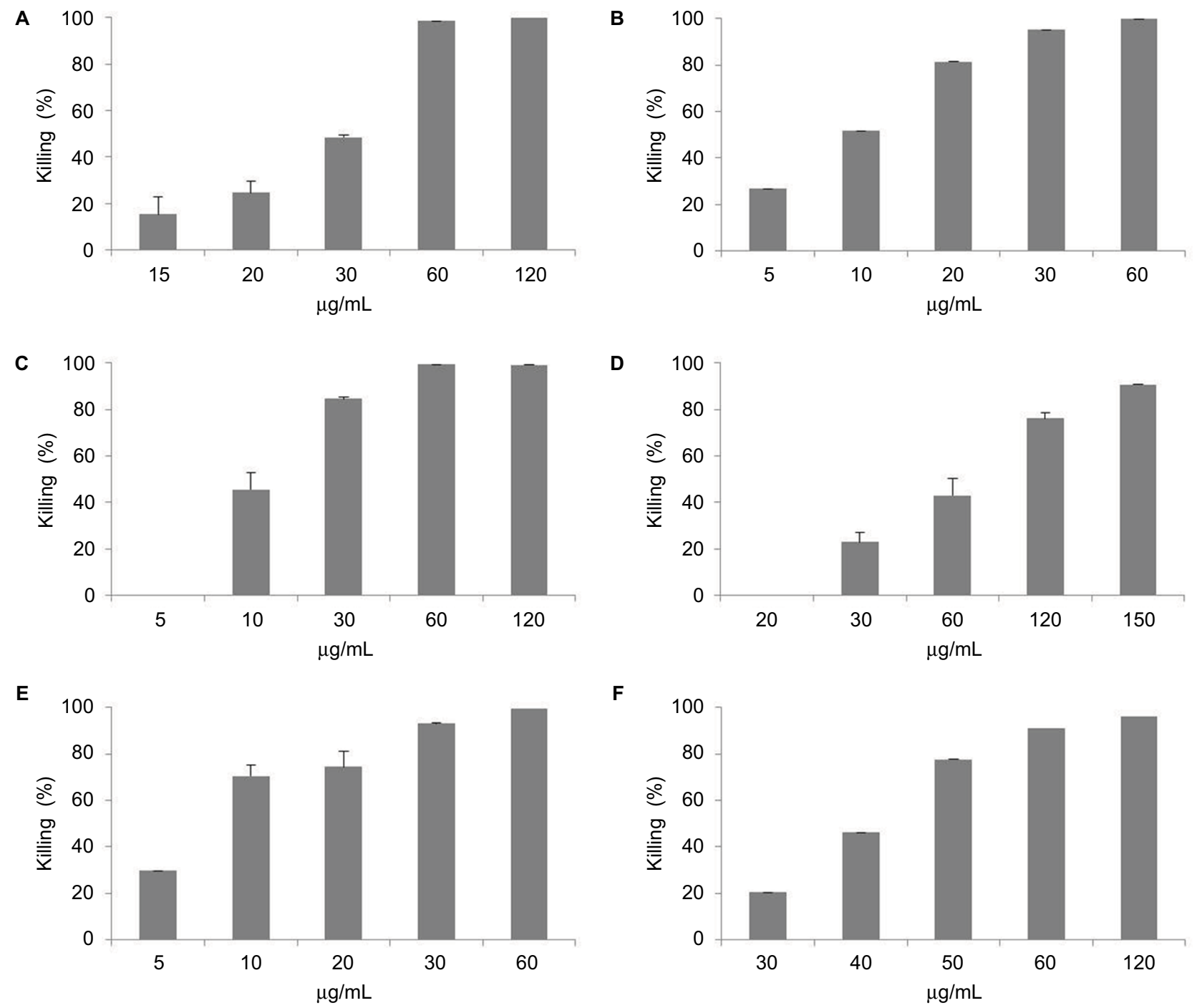

Figure SI Dose-dependent effect of SP-E against selected bacterial strains of the different tested species determined by colony-forming unit assays (CFUs).

Notes: (A) Acinetobacter baumannii 2; (B) Escherichia coli ATCC 25922; (C) E. coli I; (D) Klebsiella pneumoniae 2; (E) Pseudomonas aeruginosa ATCC 9027; and (F) Salmonella typhimurium ATCC 14028. Activity expressed as percentage killing, calculated as 100 - (average number of CFUs in peptide-treated group/average number of CFUs in control group) $\times 100$. Mean values from two independent experiments; in all cases, variability $<10 \%$. 

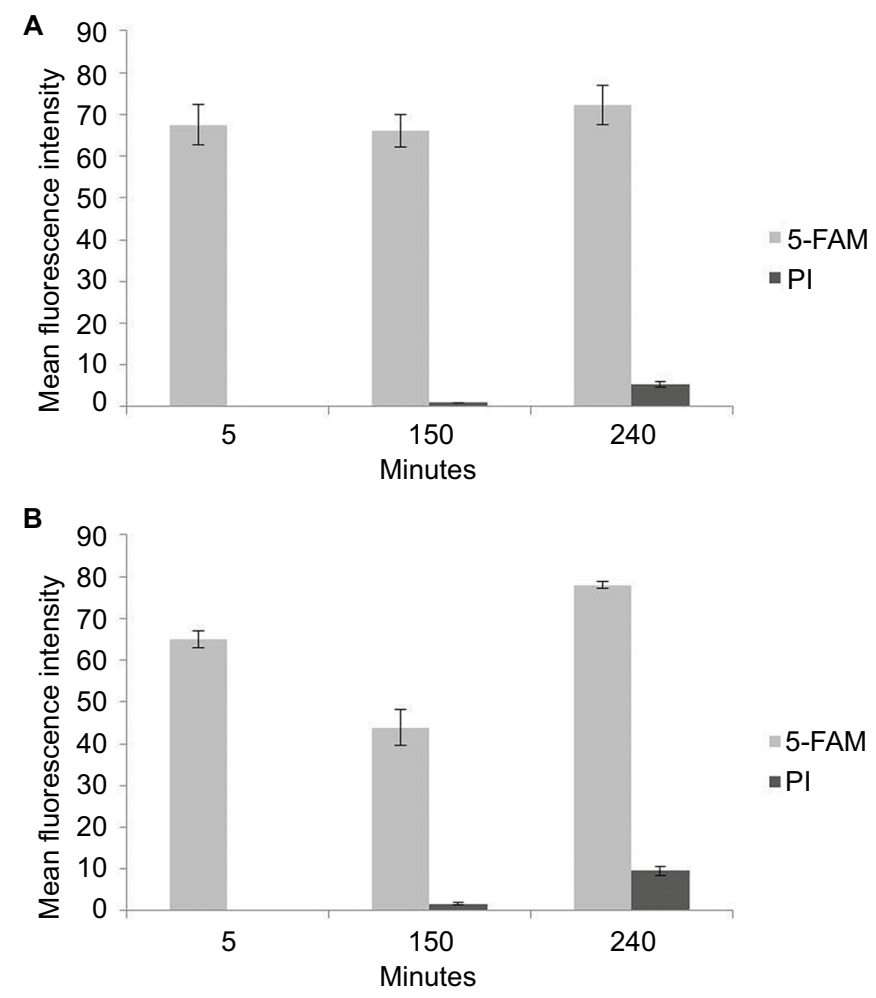

Figure S2 Mean fluorescence-intensity data obtained in confocal microscopy studies.

Notes: (A) Escherichia coli ATCC 25922 cells; and (B) Pseudomonas aeruginosa ATCC 9027 cells.

Abbreviations: Pl, propidium iodide; 5-FAM, 5-carboxyfluorescein.

Infection and Drug Resistance is an international, peer-reviewed openaccess journal that focuses on the optimal treatment of infection (bacterial, fungal and viral) and the development and institution of preventive strategies to minimize the development and spread of resistance. The journal is specifically concerned with the epidemiology of antibiotic
Dovepress

resistance and the mechanisms of resistance development and diffusion in both hospitals and the community. The manuscript management system is completely online and includes a very quick and fair peerreview system, which is all easy to use. Visit http://www.dovepress.com/ testimonials.php to read real quotes from published authors.

Submit your manuscript here: https://www.dovepress.com/infection-and-drug-resistance-journal 